\title{
Genetic Characterization of Hazelnut (Corylus avellana L.) Cultivars from Turkey Using Molecular Markers
}

\author{
Salih Kafkas ${ }^{1}$ and Yıldız Doğan \\ Department of Horticulture, Faculty of Agriculture, University of Çukurova, \\ Adana, 01330, Turkey
}

\author{
Ali Sabir \\ Department of Horticulture, Faculty of Agriculture, University of Selçu, \\ Konya, 42070, Turkey
}

\section{Ali Turan and Hasbi Seker \\ Hazelnut Research Institute, Giresun, 28200, Turkey}

Additional index words. RAPD, ISSR, AFLP, genetic similarity, PCoA

\begin{abstract}
Genetic relationships among 18 Turkish hazelnut (Corylus avellana L.) cultivars were investigated using randomly amplified polymorphic DNA (RAPD), intersimple sequence repeat (ISSR), and amplified fragment length polymorphism (AFLP) markers. Twenty-five RAPD primers, 25 ISSR primers, and eight AFLP primer pairs generated a total of 434 polymorphic marker loci. The three marker systems were able to differentiate the cultivars. Genetic similarity index values ranged from a high of 0.96 for 'Kan' and 'UzunMusa' to a low of 0.73 for 'Yassi Badem' and 'Kalinkara'. The genetic relationships were presented as an unweighted pair group method with arithmetic average (UPGMA) dendrogram and a three-dimensional principal coordinate analysis (PCoA) plot. The UPGMA dendrogram showed two main clusters, while PCoA analysis showed three groups. Cultivar-specific markers were produced by all marker systems for 10 cultivars. This study demonstrates the usefulness of molecular markers for identification of hazelnut cultivars.
\end{abstract}

The genus Corylus belongs to the Betulaceae of the order Fagales. The number of species in the genus has varied depending on the authorities due to recognition of some species as a distinct species or a subspecies, or within a certain species (Rehder, 1947; Kasapligil, 1972; Mehlenbacher, 1991; Thompson et al., 1996). The commercially important European hazelnut (Corylus avellana L.) is native to most of Europe, Turkey, and the Caucasus mountains, and wild populations can be found in these areas today. Ayfer et al. (1986) stated that Turkish cultivars are usually spontaneous hybrids of $C$. avellana $\times$ C. maxima, although the latter was suggested as a distinct species (Mehlenbacher, 1991; Thompson et al., 1996). Centuries ago, native wild hazelnut shrubs were growing in close proximity to the mountains near the Black Sea in northern Turkey. It is believed that some Turkish cultivars originated over many centuries from selection within these local wild populations (Ayfer et al., 1986). Ozkurt (1950) hypothesized that hazelnuts were first cultivated in Turkey in Giresun

Received for publication 1 June 2009. Accepted for publication 14 Aug. 2009

We express our gratitude to the Scientific Research Projects Unit (Projects No. ZF2007BAP8) of Çukurova University for financial support.

${ }^{1}$ To whom reprint requests should be addressed; e-mailskafkas@cu.edu.tr. province, and from there its cultivation spread to adjacent Ordu province. Hazelnuts are now grown along the Black Sea coast, where ecological conditions are favorable, and plantings today cover about 400,000 ha (Ayfer et al., 1986). Turkey is the world's leading producer and exporter of hazelnuts (Yavuz and Ercisli, 2006), accounting for about $70 \%$ of total production. Other important hazelnut-producing countries are Italy, the United States, Azerbaijan, Iran, Spain, and Georgia (Food and Agricultural Organization of the United Nations, 2007).

Hazelnuts from Turkey are classified based on the shape of the nut and quality of the kernel. The best-quality hazelnuts have a round shape, a high oil content, and superior aroma and taste. In spite of the crop's economic importance, no extensive studies have been conducted on genetic diversity in Turkish hazelnut germplasm. It appears that there are dozens of clones of each Turkish hazelnut cultivar in production, with a common name used for each group. In the past, cultivar identification studies have been based on morphological characters (Ayfer et al., 1986; Caliskan, 1995; Bostan et al., 1997; Erdogan and Mehlenbacher, 1997; Yao and Mehlenbacher, 2000; Koksal, 2002). In recent years, researchers around the globe have investigated genetic relationships among hazelnut cultivars using several types of molecular markers, including randomly amplified polymorphic DNA (RAPD) (Galderisi et al., 1999;
Miaja et al., 2001), amplified fragment length polymorphism (AFLP) (Ferrari et al., 2004), and simple sequence repeat (SSR) (Boccacci et al., 2006; 2008; Gokirmak et al., 2009). Palme and Vendramin (2002) used polymerase chain reaction (PCR)-RFLP to look at chloroplast variation in wild hazelnut populations. The objective of this study was to evaluate RAPD, ISSR, and AFLP markers for identifying 18 hazelnut cultivars that are economically important in Turkey.

\section{Materials and Methods}

Plant materials and DNA isolation. Eighteen hazelnut cultivars, grown primarily in the Giresun, Ordu, Trabzon, Duzce, and Izmit provinces, were used (Table 1). Leaf samples were collected from the germplasm collection of the Hazelnut Research Institute in Giresun, Turkey. DNA from young leaves was extracted according to the CTAB-based method (Doyle and Doyle, 1987) with minor modifications (Kafkas et al., 2006). The concentration of DNA solution was estimated by comparing band intensity with $\lambda$ DNA of known concentrations, after $0.8 \%$ agarose gel electrophoresis and ethidium bromide staining. DNA was diluted to $5 \mathrm{ng} \cdot \mu \mathrm{L}^{-1}$ for RAPD and ISSR analysis and to $50 \mathrm{ng} \cdot \mu \mathrm{L}^{-1}$ for AFLP reactions.

Primer selection. Initially, 160 RAPD [100 from UBC set \#4 (Michael Smith Laboratories, University of British Columbia, Vancouver, BC, Canada) and 60 in Operon sets A, G, H, R, AA, and AC from Operon Technologies, Alameda, CA], 100 ISSR primers (UBC set \#9), and 24 AFLP primer pairs were screened using seven Turkish cultivars: 'Aci', 'Cakildak', 'Incekara', 'Kalinkara', 'Palaz', 'Sivri', and 'Yuvarlak Badem'. Based on the numbers of reproducible and polymorphic fragments, 25 RAPD and 25 ISSR primers, as well as eight AFLP primer combinations were used to characterize the 18 hazelnut cultivars.

RAPD, ISSR, and AFLP analysis. RAPD and ISSR analysis followed the protocol described by Williams et al. (1990) and Zietkiewicz et al. (1994), respectively, with minor modifications (Kafkas et al., 2006). In the AFLP assay, adaptor and primer sequences, PCR conditions for preselective and selective amplifications, and selective primer designation were according to Vos et al. (1995) with minor modifications (Kafkas et al., 2008). Selective amplification was with eight primer pairs involving five $\mathrm{MseI}(\mathrm{M})$ and two EcoRI (E) primers: $\mathrm{E}_{\mathrm{AGA}} / \mathrm{M}_{\mathrm{CAC}}$, $\mathrm{E}_{\mathrm{AGA}} / \mathrm{M}_{\mathrm{CCC}}, \quad \mathrm{E}_{\mathrm{AGA}} / \mathrm{M}_{\mathrm{CCG}}, \quad \mathrm{E}_{\mathrm{AGA}} / \mathrm{M}_{\mathrm{CTC}}$, $\mathrm{E}_{\mathrm{AGT}} / \mathrm{M}_{\mathrm{CAC}}, \mathrm{E}_{\mathrm{AGT}} / \mathrm{M}_{\mathrm{CAG}}, \mathrm{E}_{\mathrm{AGT}} / \mathrm{M}_{\mathrm{CCG}}$, and $\mathrm{E}_{\mathrm{AGT}} / \mathrm{M}_{\mathrm{CTC}}$. Fragments were resolved using capillary electrophoresis on an ABI 3130xl Genetic Analyzer [Applied Biosystems Inc. (ABI), Foster City, CA] with version 3.0 of ABI data collection software. AFLP fragment analysis was performed with GeneScan Analysis Software 4.0 (ABI).

Data analysis. RAPD, ISSR, and AFLP bands were recorded as present (1) or absent (0). Only the most reproducible bands were scored and used for analysis. Scores for all 
Table 1. Nut shape groups and main cultivation areas of 18 hazelnut cultivars from Turkey.

\begin{tabular}{rlll}
\hline No. & \multicolumn{1}{c}{ Cultivars } & Main cultivation area & Nut shape group \\
\hline 1 & Aci & Ordu & Globular \\
2 & Allahverdi & Giresun & Globular \\
3 & Cakildak & Ordu & Globular \\
4 & Cavcava & Trabzon & Globular \\
5 & Fosa & Trabzon & Globular \\
6 & Incekara & Giresun & Conical \\
7 & Kalinkara & Giresun & Globular \\
8 & Kan & Giresun & Globular \\
9 & Karafindik & Düzce & Globular \\
10 & Kargalak & Trabzon & Globular \\
11 & Kus & Giresun & Conical \\
12 & Mincane & Trabzon & Globular \\
13 & Palaz & Ordu & Globular \\
14 & Sivri & Giresun & Conical \\
15 & Tombul & Giresun & Globular \\
16 & UzunMusa & Ordu & Globular \\
17 & Yassi Badem & Izmit & Long \\
18 & Yuvarlak Badem & İzmit & Long \\
\hline
\end{tabular}

${ }^{2}$ From Ayfer et al., (1986), Caliskan (1995), Okay (1999), and Koksal (2002).

Table 2. Number of bands, percentage of polymorphic bands, resolving power, and polymorphism information content of RAPD, ISSR, and AFLP markers used to fingerprint 18 Turkish hazelnut cultivars.

\begin{tabular}{lccr}
\hline & RAPD & ISSR & AFLP \\
\hline Primer number (selected/screened) & $25 / 160$ & $25 / 100$ & $8 / 24$ \\
Total number of bands & 165 & 170 & 582 \\
Mean total number of bands & 6.60 & 6.80 & 72.75 \\
No. of polymorphic bands & 96 & 99 & 239 \\
Mean no. of polymorphic bands & 3.84 & 3.96 & 29.88 \\
Polymorphism rate (\%) & 59.3 & 58.5 & 42.9 \\
Total resolving power & 87.33 & 101.75 & 220.01 \\
Average resolving power & 3.49 & 4.07 & 27.50 \\
Polymorphism information content & 0.668 & 0.661 & 0.704 \\
\hline
\end{tabular}

three types of markers, polymorphic and monomorphic, were analyzed using the NTSYSpc 2.11V program (Exeter Software, Setauket, NY) (Rohlf, 2004). Genetic similarities between hazelnut cultivars were calculated using Jaccard's coefficient (Jaccard, 1908). Mantel cophenetic correlation analysis (Mantel, 1967) was used for pairwise correspondence tests of matrices obtained from the three marker systems. Unweighted pair group method with arithmetic average (UPGMA) was performed to construct a dendrogram. The similarity matrix data were also subjected to principal coordinate analysis (PCoA) using the NTSYSpc program. The cultivars were plotted first on three dimensions using the G3D procedure of the Statistical Analysis System (SAS, 1990). The ability of the markers to differentiate the cultivars was assessed by calculating their resolving power (Rp) according to Prevost and Wilkinson (1999) using the formula $\mathrm{Rp}=$ $\sum \mathrm{Ib}$, where $\mathrm{Ib}=1-(2 \times|0.5-\mathrm{p}|)$, and $\mathrm{p}$ is the proportion of the 18 cultivars containing the I band. The polymorphism information content (PIC) of each marker was calculated using $\mathrm{PIC}=1-\sum \mathrm{Pi}^{2}$, where $\mathrm{Pi}$ is the band frequency of the $i^{\text {th }}$ allele (Smith et al., 1997).

\section{Results and Discussion}

Polymorphism and discriminating power of the markers. The level of polymorphism detected by the three marker systems was compared (Table 2). The 25 RAPD primers, chosen because they exhibited the highest level of polymorphism in the initial screening, yielded 165 DNA fragments, 3 to 13 per primer $($ mean $=6.6$ ), of which 96 were polymorphic. The number of polymorphic bands per primer ranged from 1 to 6 (mean $=$ 3.84). UBC 303 generated the highest number of bands (13), while OPAC01 produced the fewest bands (three). The highest numbers of polymorphic bands were generated by OPA08, OPA10, UBC345, and UBC368 (six each), whereas OPG02 and OPR03 produced only one polymorphic band each. Of the total number of RAPD markers scored, $59.3 \%$ were polymorphic. Primers UBC356 and UBC373 generated the highest percentage of polymorphism $(83 \%)$, whereas the lowest observed rate was $13 \%$ for OPG02. Mean PIC was 0.668 . The highest PIC was for UBC322 (0.994), and the lowest was for OPH17 (0.159) (data not shown). The average resolving power was 3.49 and total $\mathrm{Rp}$ was 87.33. UBC319 had the highest Rp (7.11), while OPR03 had the lowest (0.33). Similarly, Galderisi et al. (1999) obtained a total of one to nine bands per RAPD primer in their analysis of hazelnut cultivars, with the number of polymorphic bands ranging from zero to six. In a study of hybrid hazelnuts cultured long-term in vitro, Nas et al. (2004) detected 139 bands using 25 RAPD primers, with a mean of 5.6 bands per primer. Amplification of 18 cultivars with 25 ISSR primers gave a total of 170 bands, of which 99 were polymorphic. The total number of bands per primer ranged from four to nine, with an average of 6.8. The highest number of total bands was obtained from UBC primers 808 , 823 , and 824 , while 836 yielded the fewest bands. The number of polymorphic fragments per primer ranged from two to eight. The highest level of polymorphism was for primer UBC857 (100\%), the lowest was for primer UBC834 (28.57\%), and the mean was 58.5\%. PIC ranged from a high of 0.985 for primer UBC829 to a low of 0.335 for primer UBC 849 , with a mean of 0.622 . The average resolving power was 4.07 and total $\mathrm{Rp}$ was 101.75. UBC857 had the highest Rp (10.22), while UBC829 had the lowest (0.44) (data not shown).

The ISSR primers produced slightly more reproducible bands than the RAPD primers, in agreement with previous studies in different plant species (Goulao et al., 2001; Mattioni et al., 2002; Kafkas et al., 2006). Amplification products that were polymorphic and easily scored were obtained from primers that included TC, AC, AG, and CT repeats. ATrepeat primers yielded no amplification products, although (AT)n is thought to be the most abundant repeat motif in the plant kingdom (Morgante and Olivieri, 1993). Similar results were also reported by Casasoli et al. (2001) in chestnut (Castanea sativa Mill.) and by Kafkas et al. (2006) in pistachio (Pistacia vera $\mathrm{L}$.). ISSR analysis is quick, reproducible, and generates sufficient polymorphism in hazelnut.

In the AFLP analysis, eight AFLP primer combinations revealed a total of 582 fragments, of which 239 (42.9\%) were polymorphic. The $\mathrm{E}_{\mathrm{AGT}} / \mathrm{M}_{\mathrm{CAG}}$ primer combination generated the highest number of bands (96), while the lowest number (50 bands) was obtained from the $\mathrm{E}_{\mathrm{AGA}} / \mathrm{M}_{\mathrm{CCG}}$ primer pair. $\mathrm{E}_{\mathrm{AGT}} / \mathrm{M}_{\mathrm{CTC}}$ was the most informative primer pair based on the highest diversity estimates, including a polymorphism rate of $63.5 \%$ and a PIC value of 0.784 . The average $\mathrm{Rp}$ for AFLP markers was 27.50 and total Rp was 220.01. The $\mathrm{E}_{\mathrm{AGT}} / \mathrm{M}_{\mathrm{CAG}}$ primer pair had the highest $\mathrm{Rp}$ (36.00), while $\mathrm{E}_{\mathrm{AGA}} / \mathrm{M}_{\mathrm{CCC}}$ had the lowest (17.67) (data not shown).

The mean number of polymorphic bands was much higher for AFLP (29.88) than ISSR (3.96) or RAPD (3.84). This result is in accordance with previous comparisons of the three marker types (Patzak, 2001; Talhinhas et al., 2003; Kafkas et al., 2006). However, the polymorphism rates were lower for AFLP than for ISSR or RAPD due to the high number of monomorphic AFLP bands. The average Rp was higher for AFLP than for RAPD or ISSR. There was a slight difference between RAPD and ISSR in their average Rp values. PIC was slightly higher for AFLP than for ISSR or RAPD; the latter two having similar values (Table 2).

Correlations between marker systems based on estimates of genetic similarity. The Mantel matrix correspondence analysis was performed to compare the genetic similarities obtained according to Jaccard's coefficient. Correlation coefficients for the three markers systems were statistically significant 
and similar in magnitude: 0.62 for RAPD and ISSR, 0.64 for RAPD and AFLP, and 0.60 for ISSR and AFLP. In a study to characterize genetic diversity in pistachio germplasm, Kafkas et al. (2006) obtained similar values $(0.58-0.72)$ between the same assays. However, the type of genetic polymorphism detected by the three marker systems, the number of primers used, and the plant species may also affect the correlations among the different markers. Several types of molecular markers are available for plant germplasm characterization. Comparisons include cost, speed, reproducibility, and ability to detect polymorphism. This study shows that RAPD, ISSR, and AFLP markers are useful for identification of hazelnut cultivars. ISSR is preferable to RAPD because bands can be scored with greater confidence. ISSR and RAPD protocols are technically simple as opposed to the technically demanding AFLP method. However, AFLP seems to be more powerful than RAPD and ISSR due to the higher number of bands produced.

Genetic similarities and cluster analysis. Genetic similarity values calculated by combining data from three types of molecular markers ranged from 0.73 for the most distant cultivars to 0.96 for the closest ones. The genetic relationships among the 18 cultivars are presented as an UPGMA dendrogram (Fig. 1) and a three-dimensional plot from principal coordinate analysis (Fig. 2). The 18 cultivars were clearly separated from each other. Although the UPGMA dendrogram showed two main clusters, the PCoA figure showed three groups. The cultivars 'Yuvarlak Badem' and 'Yassi Badem' were separated from the other cultivars in both analyses.

The first group in the UPGMA dendrogram included 'Tombul', 'Sivri', and 'Kus' from Giresun, 'Mincane' and 'Fosa' from Trabzon, and 'Karafindik' from Duzce. 'Allahverdi' was the most distant cultivar in the group. The globally significant cultivar 'Tombul' was closely related $(0.85)$ to 'Sivri' (Fig. 1). Boccacci et al. (2006), using SSR markers, observed similar clustering of 'Sivri' and 'Tombul'. These two cultivars have many phenotypic differences and both are important in Giresun province. Although the names of Turkish cultivars appear to be the same name such as 'Tombul' in our study and in Boccacci et al. (2006), the genotypes, in fact, might not be the same. The second pair of closely related cultivars in this group was 'Mincane' from Trabzon and 'Kus' from Giresun (0.86).

The rest of the cultivars formed the other groups with few cultivars. For example, Group II was comprised of 'Cavcava', 'Acı', and 'Kargalak' cultivars. 'Kargalak' is also known as 'Karidaty' or 'Imperial de Trebizonde' (Boccacci et al., 2006). In this group, 'Cavcava' and 'Aci' formed a pairwise combination, while 'Kargalak' surrounded them at a relatively lower point. 'Cavcava' and 'Aci' resemble each other in several morphological properties, including a semierect growth habit, green bud color, red style color, and moderately hairy husks, although

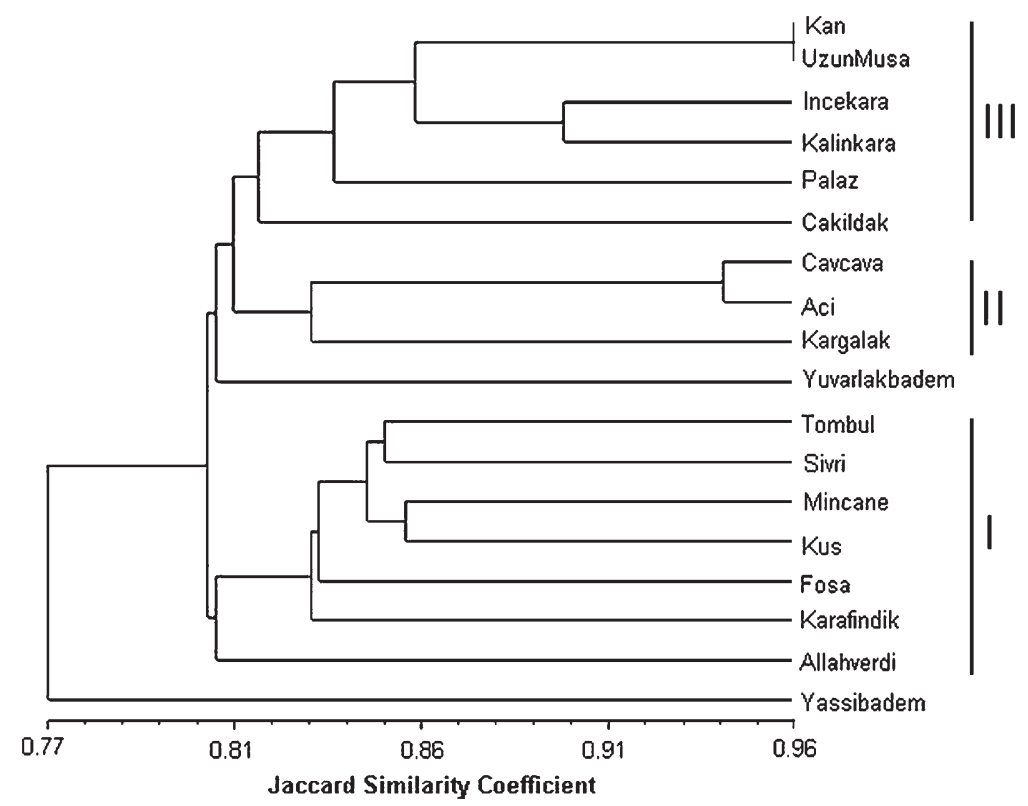

Fig. 1. Dendrogram of 18 hazelnut cultivars resulting from the unweighted pair-group method of arithmetic average cluster analysis based on Jaccard's similarity coefficient obtained from 165 RAPD, 170 ISSR, and 582 AFLP markers.

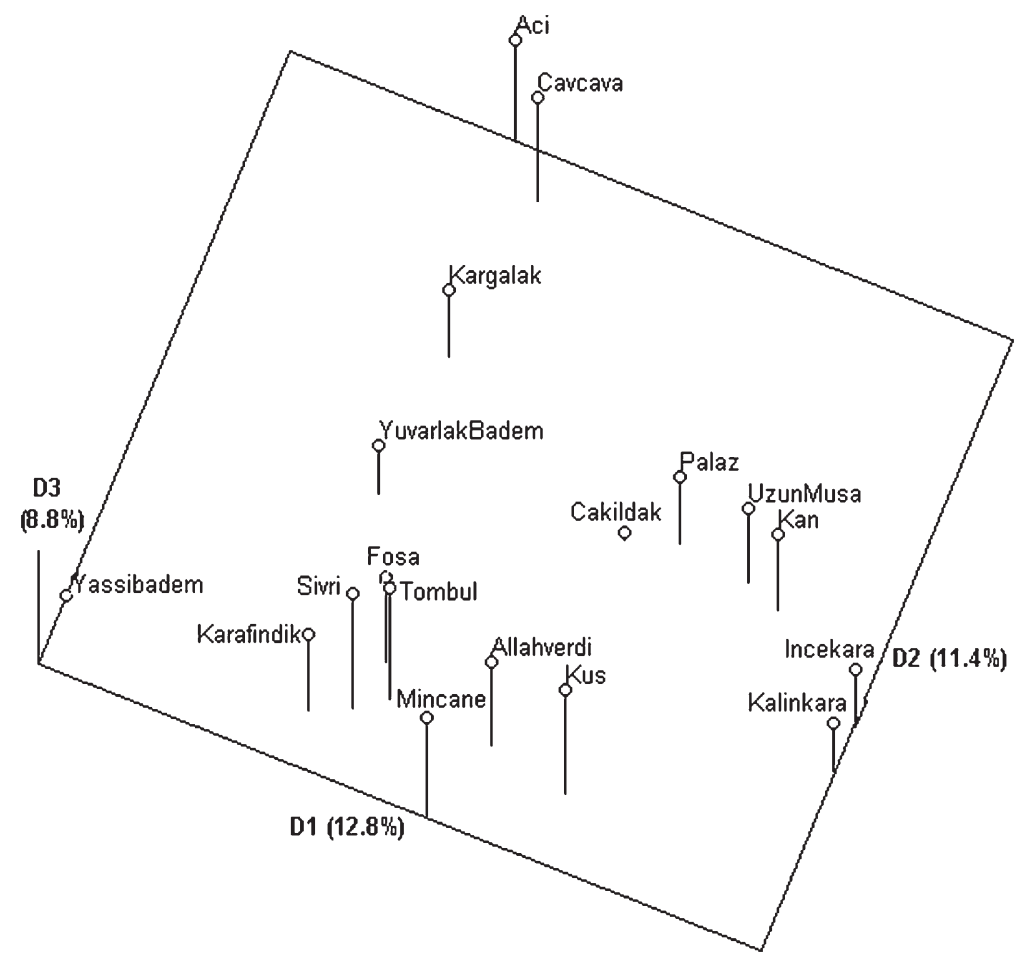

Fig. 2. Principal coordinate analysis of 18 hazelnut cultivars resulting from analysis of 165 RAPD, 170 ISSR, and 582 AFLP markers.

their growing areas are Trabzon and Ordu provinces, respectively (Caliskan, 1995).

Group III included six cultivars: 'Cakildak', 'Palaz', 'UzunMusa', 'Kan', 'Incekara', and 'Kalinkara'. In this group, the highest genetic similarity was found between 'Kan' and 'UzunMusa'. In terms of morphology, this proximity could supposedly have arisen from certain shared features such as nut shape (globular), bud shape (oval), and hair density on the husk (medium), as well as their main cultivation area (Ordu province). 'Incekara' and 'Kalinkara', both from Giresun, also grouped together (0.90) on the UPGMA dendrogram. In their SSR analysis of several Turkish and foreign hazelnut cultivars, Boccacci et al. (2006) found a close relationship between 'Kalinkara' and 'Incekara'. 'Yassi Badem' and 'Yuvarlak Badem' are grown in Izmit province, east of the Marmara 
region, and far from the main growing region. 'Yassi Badem' was distant from all the other cultivars (0.77), and 'Yuvarlak Badem' was placed between Group I and Group II.

Cultivar-specific markers. Cultivar-specific markers were produced by five RAPD and four ISSR primers, and eight AFLP primer pairs. The total number of cultivarspecific markers was seven RAPDs, five ISSRs and 22 AFLPs (Table 3), for a total of 34 markers in 10 cultivars. The cultivarspecific markers generated by ISSR primers UBC814 and UBC824 and RAPD primers OPR12 and UBC393 are shown in Fig. 3.

AFLP produced a greater number of specific markers and a higher total number of markers. The $\mathrm{E}_{\mathrm{AGA}} / \mathrm{M}_{\mathrm{CCG}}$ AFLP primer combination was the most useful, producing five markers specific to five different hazelnut cultivars (Table 3). $\mathrm{E}_{\mathrm{AGT}} / \mathrm{M}_{\mathrm{CTC}}$ and $\mathrm{E}_{\mathrm{AGT}} / \mathrm{M}_{\mathrm{CAG}}$ primer pairs were next in terms of usefulness, producing five and four markers, respectively. Such markers should further aid researchers seeking to identify particular cultivars with certain primers. For example, it is very difficult to distinguish the real 'Tombul' from its many clones in the Black Sea region of Turkey based solely on morphological traits. Cultivar-specific DNA markers would also provide an additional tool for the identification of hazelnut germplasm of unknown origin.

In conclusion, we employed RAPD markers, ISSR markers, and fluorescent AFLP

Table 3. Cultivar-specific markers for 10 Turkish hazelnut cultivars generated by RAPD, AFLP and ISSR assays.

\begin{tabular}{|c|c|c|c|}
\hline Cultivars & RAPD & ISSR & AFLP \\
\hline$\overline{\text { Aci }}$ & & & EAGA/MCCG 437 \\
\hline Allahverdi & UBC393960 & $\mathrm{UBC} 24_{510}$ & $\mathrm{EAGA}_{\mathrm{MCTC}} \mathrm{M}_{25}$ \\
\hline Cakildak & & $\mathrm{UBC} 84_{1250}$ & $\mathrm{EAGA} \mathrm{MCAC}_{382}, \mathrm{EAGA} \mathrm{MCAC}_{443}$, \\
\hline Fosa & & $\mathrm{UBC} 843_{1550}$ & $\begin{array}{l}\text { EAGT/MCTC }_{135}, \text { EAGT/MCTC } \\
\text { EAGA/MCCG }_{167}, \text { EAGA/MCTC }_{109} \text {, } \\
\text { EAGA/MCTC }_{431}\end{array}$ \\
\hline Kalinkara & $\begin{array}{l}\text { OPR } 12_{1350} \\
\text { UBC } 303_{1370}\end{array}$ & & $\begin{array}{l}\text { EAGT/MCAG }_{142}, \text { EAGA/MCCG } \\
\text { EAGT }_{25} \text {, } \\
\text { MCTC }_{455}\end{array}$ \\
\hline Karafindik & & & EAGT/MCAG 318 \\
\hline Kargalak & & & $\begin{array}{l}\text { EAGT/MCAC }_{272}, \text { EAGA/MCCG } \\
\text { EAGT/MCTC }_{178}, \text { EAGT/MCTC } \\
\text { EAf }_{286}\end{array}$ \\
\hline Palaz & $\begin{array}{l}\text { UBC } 345_{750} \\
\text { UBC } 368_{900}\end{array}$ & $\mathrm{UBC} 814_{1800}$ & \\
\hline Sivri & & & EAGA/MCCG ${ }_{96}$ \\
\hline Yassi Badem & $\mathrm{UBC} 345_{1600}$ & $\mathrm{UBC} 813_{1250}$ & $\begin{array}{l}\text { EAGA/MCAC }{ }_{218}, \text { EAGT/MCAG } \\
\text { EAGT/MCAG }_{386}, \mathrm{MAGA}_{34 \mathrm{MCCC}_{432}}\end{array}$ \\
\hline
\end{tabular}

$\begin{array}{llllllllllllllllll}1 & 2 & 3 & 4 & 5 & 6 & 7 & 8 & 9 & 10 & 11 & 12 & 13 & 14 & 15 & 16 & 17 & 18\end{array}$

A

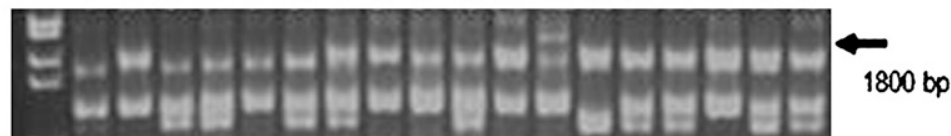

B

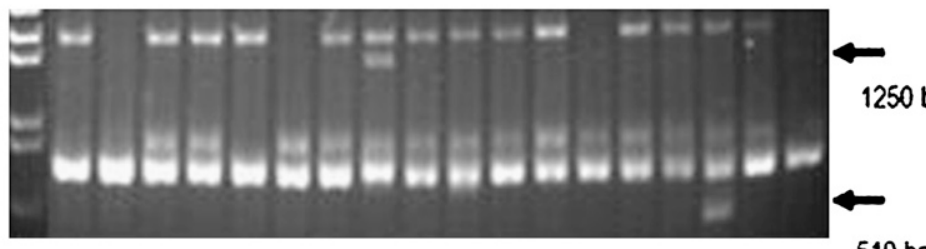

$510 \mathrm{bp}$

C

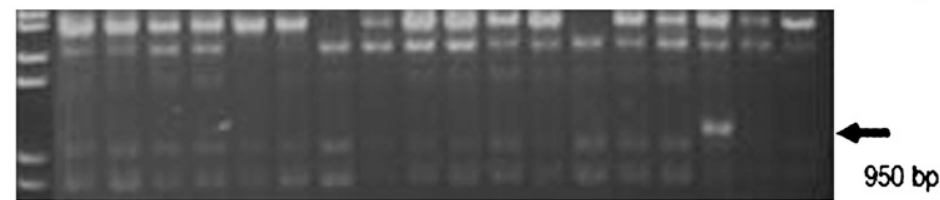

D

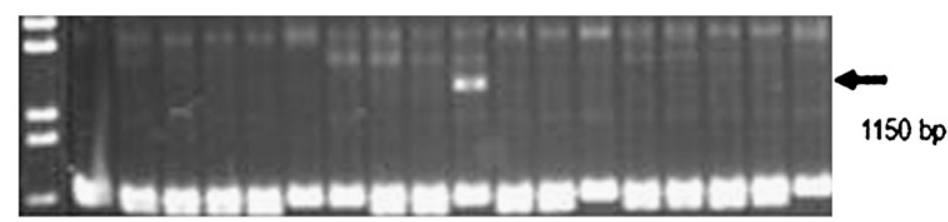

Fig. 3. Some cultivar-specific markers generated in (A) 'Palaz' by ISSR primer UBC814, (B) 'Cakildak' and 'Allahverdi' by ISSR primer UBC824, (C) 'Allahverdi' by RAPD primer UBC393, and (D) 'Kalinkara' by RAPD primer OPR12. The order of the cultivars is 'Cavcava', 'Yassi Badem', 'Kan', 'Uzun Musa', 'Aci', 'Kargalak', 'Yuvarlak Badem', 'Cakildak', 'Incekara', 'Kalinkara', 'Tombul', 'Palaz', 'Sivri', 'Mincane', 'Fosa', 'Allahverdi', 'Kus', and 'Karafindik', respectively. markers for the assessment of genetic relationships among 18 Turkish hazelnuts cultivars, several of which have great economic importance. Our results may benefit breeders in selecting the most diverse cultivars with favorable characteristics to start crossing and selection programs.

\section{Literature Cited}

Ayfer, M., A. Uzun, and F. Bas. 1986. Turkish hazelnut cultivars. Karadeniz Bolgesi Ihracatcilar Birligi Giresun

Boccacci, P., A. Akkak, and R. Botta. 2006. DNA typing and genetic relationship among European hazelnut (Coryllus avellana L.) cultivars using microsatellite markers. Genome 49:598611.

Boccacci, P., R. Botta, and M. Rovira. 2008. Genetic diversity of hazelnut (Corylus avellana L.) germplasm in Northeastern Spain. HortScience 43:667-672.

Bostan, Z.S., A. Islam, and S. Sen. 1997. Investigation on nut develeopment in hazelnuts and determination of nut characteristic and variation within cultivars in some hazelnut cultivars. Acta Hort. 445:101-107.

Caliskan, T. 1995. Findik cesit katalogu. Tarim Koyisleri Bakanligi, Tarımsal Uretim ve Gelistirme Gen. Mud., Bitkisel Uretim Gelistirme Dairesi Bsk., Ankara.

Casasoli, M., C. Mattioni, M. Cherubini, and F. Villani. 2001. Genetic linkage map of European chestnut (Castanea sativa Mill.) based on RAPD, ISSR and isozyme markers. Theor. Appl. Genet. 102:1190-1199.

Doyle, J.J. and J.L. Doyle. 1987. A rapid isolation procedure for small quantities of fresh leaf tissue. Phytochem. Bul. J. 19:11-15.

Erdogan, V. and S.A. Mehlenbacher. 1997. Preliminary result on interspecific hybridization in Corylus. Acta Hort. 445:65-68.

Ferrari, M., M. Gori, R. Monnanni, M. Buiatti, G.T. Scarascia Mugnozza, and C. De Pace. 2004 DNA fingerprinting of Corylus avellana L. accessions revealed by AFLP molecular markers. Acta Hort. 686:125-134.

Food and Agricultural Organization of the United Nations. 2007. Agriculture data [online]. 14 Nov. 2008. <http://faostat.fao.org/site/567/ default.aspx $>$.

Galderisi, U., M. Cipollaro, G. Di Bernardo, L. De Masi, G. Galano, and A. Cascino. 1999. Identification of hazelnut (Corylus avellana L.) cultivars by RAPD analysis. Plant Cell Rep. 18:652-655.

Gokirmak, T., S.A. Mehlenbacher, and N.A. Bassil. 2009. Characterization of European hazelnut (Corylus avellana) cultivars using SSR markers. Genet. Resources Crop Evol. 56: 147-172.

Goulao, L., T. Valdiviesso, C. Santana, and C.M. Oliveira. 2001. Comparison between phenetic characterization using RAPD and ISSR markers and phenotypic data of cultivated chestnut (Castanea sativa Mill.). Genet. Resources Crop Evol. 48:329-338.

Jaccard, P. 1908. Nouvelle reserches sur la distribution florale. Bul. Soc. Vaud. Sci. Nat. 44: 223-227.

Kafkas, S., H. Ozkan, B.E. Ak, I. Acar, H.S. Atli, and S. Koyuncu. 2006. Detecting DNA polymorphism and genetic diversity in a wide pistachio germplasm: Comparison of AFLP, ISSR and RAPD markers. J. Amer. Soc. Hort. Sci. 131:522-529.

Kafkas, S., M. Ozgen, Y. Dogan, B. Ozcan, S. Ercisli, and S. Serce. 2008. Molecular characterization 
of mulberry accessions in Turkey by AFLP markers. J. Amer. Soc. Hort. Sci. 133:593597.

Kasapligil, B. 1972. A bibliography on Corylus (Betulaceae) with annotations. Annu. Rep. North. Nut Grow. Assoc. 63:107-162.

Koksal, A.I. 2002. Turkish hazelnut cultivars. Hazelnut Promotion Group ISBN: 975-92886$1-3$.

Mantel, N. 1967. The detection of disease clustering and generalized regression approach. Cancer Res. 27:209-220.

Mattioni, C., M. Casasoli, M. Gonzalez, R. Ipinza, and F. Villani. 2002. Comparison of ISSR and RAPD markers to characterize three Chilean Nothofagus species. Theor. Appl. Genet. 104: 1064-1070.

Mehlenbacher, S.A. 1991. Hazelnuts (Corylus). Genetic resources of temperate fruit and nut crops. Acta Hort. 290:791-836.

Miaja, M.L., R. Vallania, C. Me, Akkak, O. Nassi, and G. Lepori. 2001. Varietal characterization in hazelnut by RAPD markers. Acta Hort. 556:247-250.

Morgante, M. and A.M. Olivieri. 1993. PCRamplified microsatellites as markers in plant genetics. Plant J. 3:175-182.

Nas, M.N., N. Mutlu, and P.E. Read. 2004. Random amplified polymorphic DNA (RAPD) analysis of long-term cultured hybrid hazelnut. HortScience 39:1079-1082.
Okay, A.N. 1999. Allahverdi Findik Cesidinin Tanimlanmasi, Tarim ve Koyisleri Bakanligi, Tarimsal Arastirmalar Genel Mudurlugu, Findik Arastirma Enstitusu Mudurlugu, Giresun.

Ozkurt, A.S. 1950. Findik ekimi, findiklara zarar veren bocekler mucadelesi, hastaliklari, tedavisi ve findigin ekonomideki durumu, Tarim Bakanligi, Nesriyet Mudurlugu, Sayi 676.

Palme, A.E. and G.G. Vendramin. 2002. Chloroplast DNA variation, postglacial recolonization and hybridization in hazel, Coryllus avellana. Mol. Ecol. 11:1769-1779.

Patzak, J. 2001. Comparison of RAPD, STS, ISSR and AFLP molecular methods used for assessment of genetic diversity in hop (Humulus lupulus L.). Euphytica 121:129-138.

Prevost, A. and M.J. Wilkinson. 1999. A new system of comparing PCR primers applied to ISSR fingerprinting of potato cultivars. Theor. Appl. Genet. 98:107-112.

Rehder, A. 1947. Manual of cultivated trees and shrubs hardy in North America. 2nd ed. Macmillan Publishing Company, New York.

Rohlf, F.J. 2004. NTSYS-pc numerical taxonomy and multivariate analysis system. Version 2.11V. Exeter software, Setauket, New York.

SAS Institute Inc. 1990. SAS users guide; SAS/ STAT, version 6. SAS Inst. Inc., Cary, N.C.

Smith, J.S.C., E.C.L. Chin, H. Shu, O.S. Smith, S.J. Wall, M.L. Senior, S.E. Mitchell, S. Kresovich, and J. Ziegle. 1997. An evaluation of the utility of SSR loci as molecular markers in maize ( $\mathrm{Zea}$ mays L.): Comparisons with data from RFLPs and pedigree. Theor. Appl. Genet. 95:163-173.

Talhinhas, P., J. Neves-Martins, and J. Leitao. 2003. AFLP, ISSR and RAPD markers reveal high levels of genetic diversity among Lupinus spp. Plant Breed. 122:507-510.

Thompson, M.M., H.B. Lagerstedt, and S.A. Mehlenbacher. 1996. Hazelnuts, p. 125-184. In: Janick, J., J.N. Moore (eds.). Fruit breeding, Vol. 3, Nuts. John Wiley \& Sons, New York.

Vos, P., L. Hogers, M. Bleeker, T. Van De Lee, M. Hornes, A. Frijters, J. Pot, J. Peleman, M Kuiper, and M. Zabeau. 1995. AFLP: A new technique for DNA fingerprinting. Nucleic Acids Res. 23:4407-4414.

Williams, J.G.K., A.R. Kubelik, K.J. Livak, J.A. Rafalski, and S.V. Tingey. 1990. DNA polymorphism amplified by arbitrary primers are useful as genetic markers. Nucleic Acids Res. 18:6531-6535.

Yao, Q. and S.A. Mehlenbacher. 2000. Heritability, variance components and correlation of morphological and phenological traits in hazelnut. Plant Breed. 119:369-381.

Yavuz, F. and S. Ercisli. 2006. Outlook for Turkey's hazelnut sector. Outlook Agr. 35:73-78.

Zietkiewicz, E., A. Rafalski, and D. Labuda. 1994. Genome fingerprinting by simple sequence repeat (SSR)-anchored polymerase chain reaction amplification. Genomics 20:176-183. 